\title{
ANÁLISE DA DESIDRATAÇÃO DE RESÍDUOS DE PROCESSAMENTO DO MARACUJÁ UTILIZANDO UM MICROONDAS DOMÉSTICO
}

\author{
L.M.RODRIGUES ${ }^{1}$; L.C.PRATA ${ }^{1}$; M.D.SILVA ${ }^{1}$; N.C.SILVA ${ }^{1}$; C.R.DUARTE ${ }^{1}$; M.A.S. \\ BARROZO $^{1}$ \\ ${ }^{1}$ Universidade Federal de Uberlândia, Faculdade de Engenharia Química \\ E-mail para contato: lorrayneemartins@hotmail.com
}

\begin{abstract}
RESUMO - O Brasil tem se destacado na produção mundial de frutas, sendo que os altos índices de produtividade e os resultados comerciais são fatores que demonstram um crescimento desse setor nos últimos anos. Ao mesmo tempo, tal expansão gerou também um incremento na quantidade de resíduos gerados que muitas vezes são simplesmente descartados pelas indústrias. Assim, agregar valor a estes resíduos é de extremo interesse, pois é provado que os mesmos possuem grandes quantidades de compostos como vitaminas, antioxidantes e fibras. Ao mesmo tempo, o processo de desidratação tem se mostrado como uma das formas mais simples de conservação de alimentos, sendo que a utilização de microondas tem apresentado alto desempenho quanto a tempo e uniformidade energética, quando comparada aos métodos convencionais. Sendo assim, o objetivo desse trabalho é fazer uma análise da desidratação do resíduo de maracujá utilizando um microondas doméstico e vendo seus efeitos para uma possível utilização futura.
\end{abstract}

\section{INTRODUÇÃO}

O Brasil é o terceiro produtor mundial de frutas, com uma produção anual de mais de 43 milhões de toneladas. Mesmo sendo um dos principais produtores de alimentos, ainda enfrenta a realidade do desperdício em todas as etapas da cadeia produtiva. Resíduos industriais são atualmente considerados uma problemática ambiental, devido ao grande volume gerado, a presença de materiais perigosos ao meio ambiente, à saúde pública e à dificuldade crescente de se conseguir áreas para a sua disposição (EMPRAPA, 2012). Na maior parte das vezes não possuem uma destinação adequada, sendo simplesmente descartados pelas empresas ou no máximo, utilizados como ração.

Vários estudos vêm sendo realizados nas mais diferentes partes do mundo e têm mostrado que esses resíduos, inicialmente sem interesse industrial, podem apresentar uma grande quantidade de compostos úteis à nutrição humana e animal, os chamados compostos funcionais e/ou bioativos, dos quais se destacam as vitaminas, minerais, fibras e substâncias de elevada capacidade antioxidante, como o ácido ascórbico e cítrico (UCHÔA, 2007).

Em paralelo, a utilização de processos de desidratação em alimentos vem sendo feita há muitos anos e com resultados bastante satisfatórios, já que tem se mostrado como um dos métodos mais simples, baratos e efetivos de conservação de alimentos, eliminando uma grande quantidade de água dos mesmos, o que impede a proliferação das bactérias e outros 
microoganismos que tornariam a vida útil (ou de prateleira) destes alimentos bastante reduzida (BORTOLOTTI, 2012).

O maracujá e seus resíduos apresentam uma série de compostos bioativos e nutrientes de importância considerável. Entretanto, um dos seus diferenciais é a grande presença de fibras solúveis e insolúveis, principalmente a pectina. Estudos têm apontado que essas fibras, encontradas principalmente na casca e albedo do maracujá, apresentam também um grande potencial para serem aplicadas como fibras dietéticas, no combate a diabetes e colesterol, o que torna o resíduo desse fruto de bastante interesse nesse projeto.

Dessa forma e após tudo que foi explanado anteriormente o objetivo desse trabalho foi realizar a desidratação do resíduo de maracujá utilizando um microondas convencional doméstico e verificar seu comportamento através de curvas de secagem (tempo x umidade) e análises de alguns compostos bioativos (teor de fenólicos, flavonoides, ácido cítrico e ácido ascórbico).

\section{MATERIAIS E MÉTODOS}

O resíduo de maracujá foi fornecido pela empresa Lotus Soluções Ambientais, localizada na cidade de Araguari-MG. Utilizou-se um microondas doméstico de potência nominal $800 \mathrm{~W}$ adaptado com um sistema de pesagem para medição em tempo real da massa do material durante a desidratação. Para cada experimento utilizou-se 120 gramas do material, homogeneamente distribuído a fim de garantir uma desidratação mais uniforme possível.

O testes preliminares levaram a um planejamento experimental do tipo fatorial $4^{\mathrm{K}}$, levando em conta duas variáveis: Tempo $(5,10,15$ e 20 minutos) e Potência $(280 \mathrm{~W}, 480 \mathrm{~W}$, $600 \mathrm{~W}$ e $800 \mathrm{~W}$ ) ajustadas manualmente no display do equipamento. A amostra final póssecagem também tinha sua umidade medida e passava por uma série de análises para verificar as condições dos compostos bioativos presentes no resíduo após a desidratação.

Além do comportamento da retirada de umidade, tanto o resíduo in natura (antes da desidratação) quanto o resíduo desidratado passaram por uma série de análises físicoquimicas para avaliar a presença de compostos bioativos e antioxidantes nos mesmos. Foram verificados o teor de Flavonóides Totais(determinado pelo método colorimétrico descrito por Zhishen et.al 1999 e expressos em mg de rutina/100 g de amostra em base seca), teor de Fenólicos Totais (determinado pelo método de Folin Ciocalteau Singleton \& Rossi, 1965 e expresso em $\mathrm{mg}$ de ácido gálico/100 g de amostra em base seca), teor de Acidez Total Titulável (ATT)(através da titulação com $\mathrm{NaOH}$ e expresso por mg de ácido cítrico/100 g de amostra em base seca - AOAC, 1995) e teor de Ácido Ascórbico (AA) ou Vitamina C(obtido por titulometria, através da redução do 2,6-diclorofenol-indofenol, com os resultados expressos em $\mathrm{mg}$ de ácido ascórbico/100 g de amostra em base seca - AOAC, 1995). A umidade final das amostras foi calculada através do método da estufa a $105{ }^{\circ} \mathrm{C} \pm 3{ }^{\circ} \mathrm{C}$ por 24 horas.

Desse modo, ao finalizar todas as etapas de análise, foi possível determinar a eficiência desse método de desidratação e seu impacto nos principais compostos antioxidantes. 


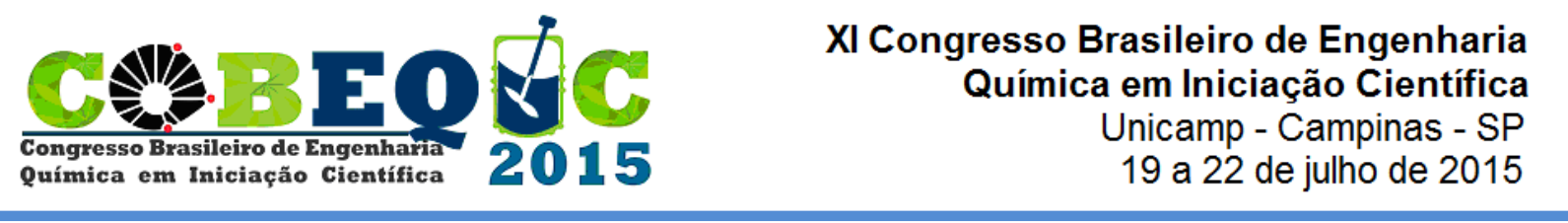

\section{RESULTADOS DE DISCUSSÕES}

\subsection{Compostos Bioativos}

Resíduo in natura: Primeiramente, foram realizadas as análises para o resíduo in natura (antes da desidratação), que será utilizado como base de comparação. Os resultados estão apresentados na Tabela 1.

Tabela 1 - Resíduo in natura (Umidade de 82,9)

\begin{tabular}{|c|c|}
\hline ANÁLISE & RESULTADO \\
\hline FLAVONÓIDES & $0,4470 \mathrm{mg}$ rutina/100 g sólido seco \\
\hline FENÓLICOS & $122,1298 \mathrm{mg}$ ácido gálico $/ 100 \mathrm{~g}$ sólido seco \\
\hline ACIDEZ & $2701,3503 \mathrm{mg}$ ácido cítrico $/ 100 \mathrm{~g}$ sólido seco \\
\hline VITAMINA C & $0,5353 \mathrm{mg}$ ácido ascórbico $/ 100 \mathrm{~g}$ sólido seco \\
\hline
\end{tabular}

Teor de flavonoides: Sobre os flavonoides, observados na Figura 1, devemos destacar o excelente desempenho da secagem do resíduo na potência de $480 \mathrm{~W}$. Isto porque houve um crescimento contínuo do seu teor, ao longo do tempo decorrido durante o processo, já em nenhum momento ocorreu queda, diferentemente da potência de $800 \mathrm{~W}$, onde foi observada um declínio no intervalo de tempo de 10 a 15 minutos. Além disso, a potência evidenciada foi a que apresentou o maior teor de flavonoides, quando atingiram os 20 minutos de secagem.

Figura 1 - Teor de flavonoides em relação ao tempo.

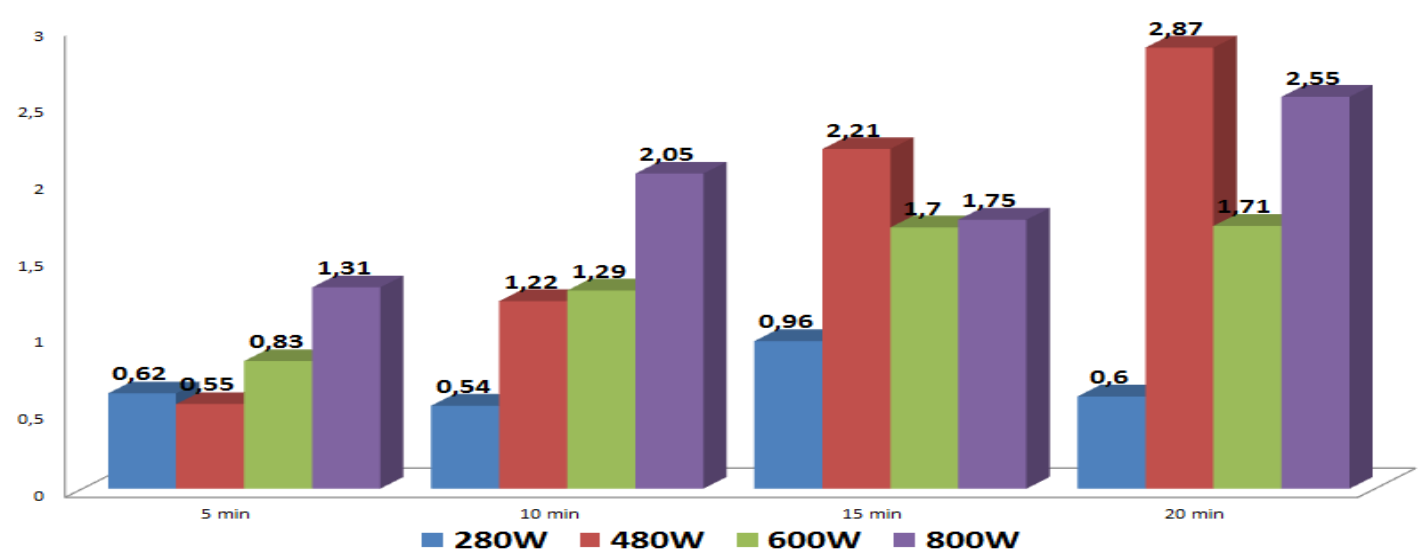

Teor de fenólicos: Observando a Figura 2, nota-se que a potência de $480 \mathrm{~W}$ foi a que apresentou melhor desempenho, se considerarmos o teor de fenólicos durante o processo de desidratação do resíduo de maracujá. Ao analisarmos entre os 5 e 10 minutos, a maioria das potências (exceto a de $280 \mathrm{~W}$ ) estavam com quantidades de fenólicos bem próximas, sendo que para a potência de $600 \mathrm{~W}$, o teor era o maior neste intervalo. O fator determinante foi após os 10 minutos, quando as outras potências diminuíram o seu teor e a potência evidenciada (480W), só aumentou o teor de fenólicos em relação as outras, ficando em maior quantidade no tempo de 15 minutos. 
Figura 2 - Teor de flavonoides em relação ao tempo.

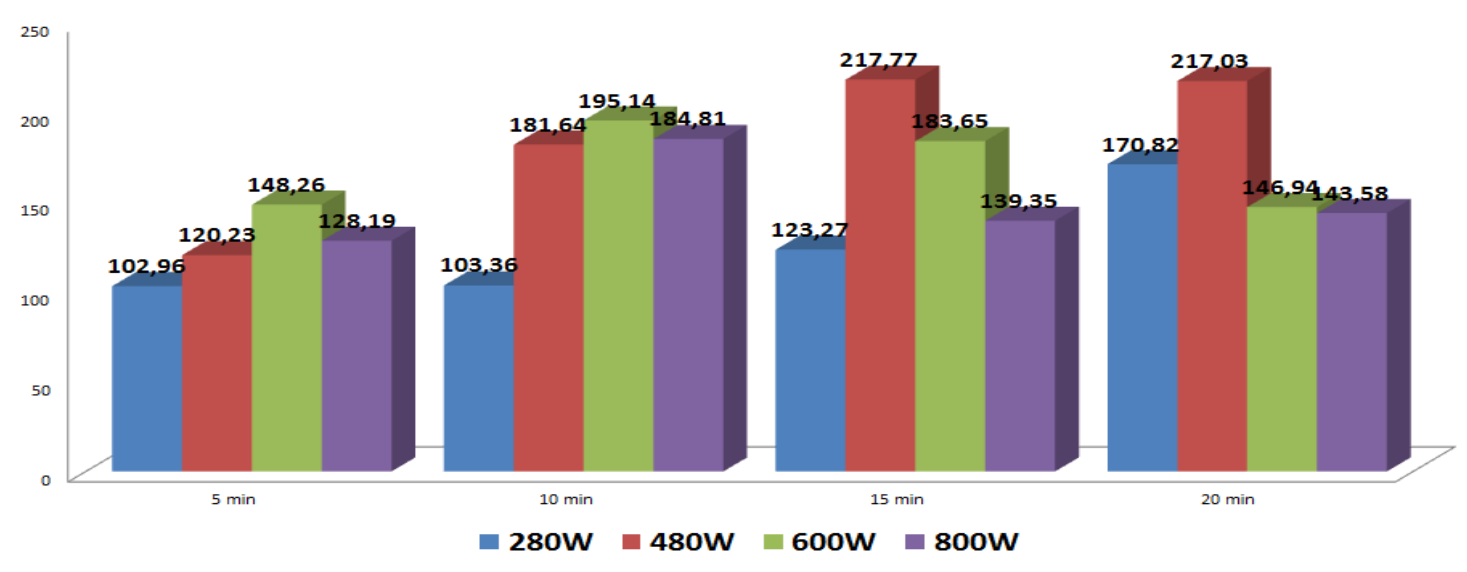

Teor de Vitamina C: A análise do teor de vitamina $C$ está mostrada na Figura 3. Mais uma vez, deve-se evidenciar o desempenho da potência $480 \mathrm{~W}$, desta vez, diante do teor de vitamina C. Esta última, juntamente com a de $800 \mathrm{~W}$, foram as únicas que não apresentaram decrescimento ao longo do tempo, porém, a potência máxima pode deteriorar ou até queimar o resíduo. Sendo assim, o melhor resultado, primeiramente por apresentar o maior teor de vitamina $\mathrm{C}$ aos 20 minutos de secagem, segundo, por não degradar a amostra, por ser uma potencia relativamente baixa é a de $480 \mathrm{~W}$.

Figura 3 - Teor de Vitamina C em relação ao tempo.

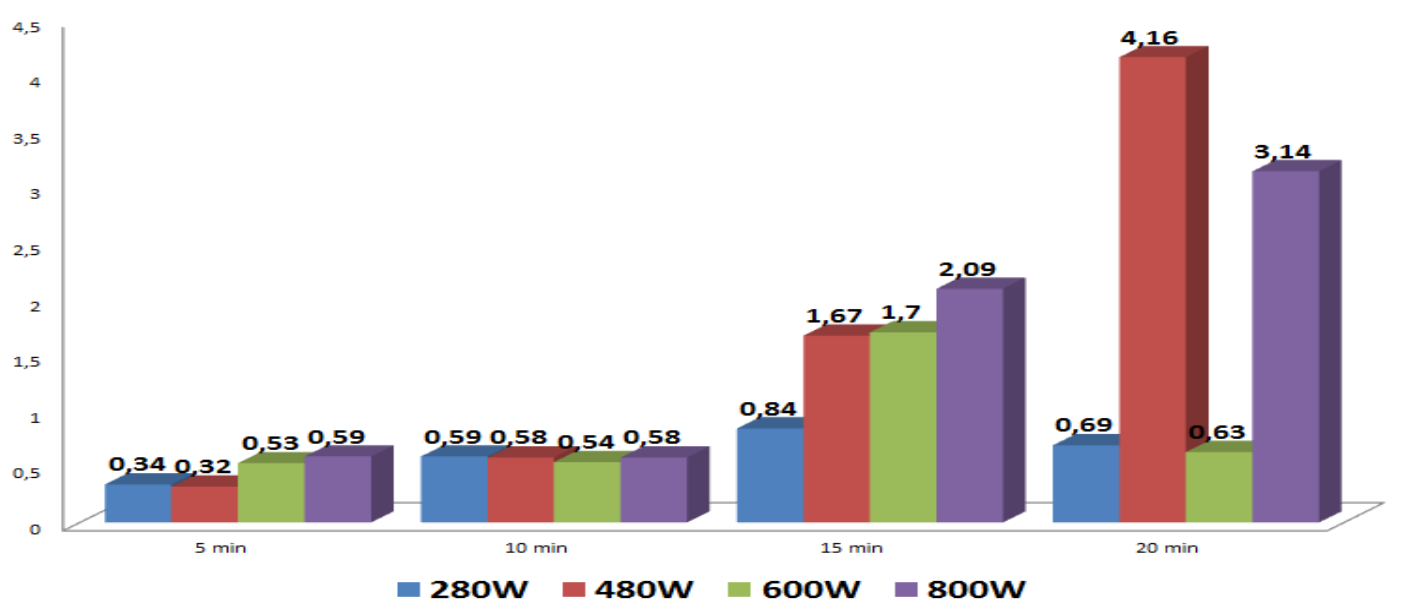

Teor de Acidez: Mostrada na Figura 4, à medida que secamos o resíduo, perde-se um grande teor de acidez, que antes era muito alto na amostra In Natura. O melhor desempenho, neste caso, era de se esperar que fosse a uma baixa potência e em uma pequena quantidade de tempo. O que se observou foi um melhor resultado para a potência de $480 \mathrm{~W}$, após 10 minutos iniciado o processo. Mas depois desse tempo, ocorreu o que era esperado: a queda do teor de acidez, assim como aconteceu com as outras potências.

Figura 4 - Ter de acidez em relação ao tempo. 


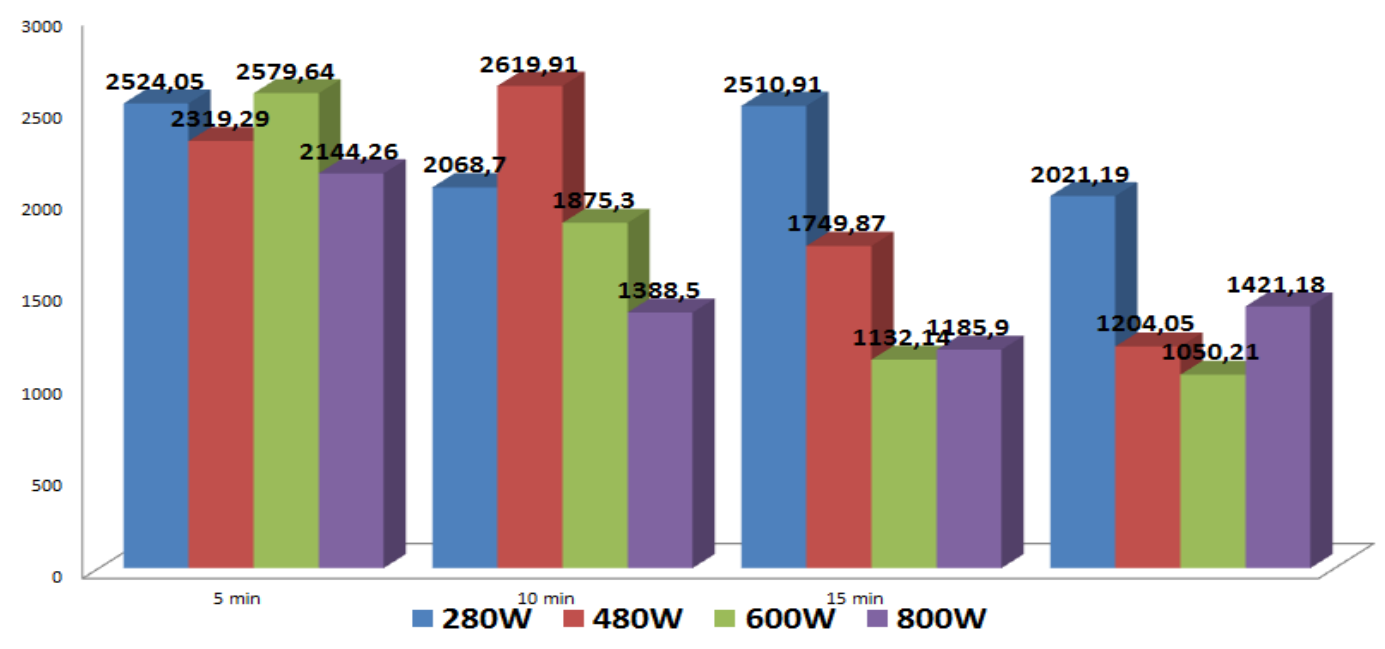

\subsection{Curvas de Desidratação}

Diante da curva de secagem, percebe-se claramente que as mais altas potências (600 $\mathrm{W}$ e $800 \mathrm{~W}$ ) apresentam resultados mais satisfatórios, por retirarem grande parte da umidade do resíduo In Natura. O pico de maior retirada do microondas com potência a $600 \mathrm{~W}$ é no intervalo de 10 a 15 minuto, já quando aumenta-se a potência para $800 \mathrm{~W}$, um maior rendimento é visto entre os 5 e 10 minutos. Não devemos deixar de destacar o resultado apresentado quando coloca-se a potência de $480 \mathrm{~W}$, porque apesar da baixa intensidade das ondas, a desidratação foi muito satisfatória, principalmente quando compararmos a de $280 \mathrm{~W}$, se assemelhando com o rendimento das potências mais altas. Portanto, se levarmos em consideração todos esses dados, credita-se um bom rendimento à potência de $480 \mathrm{~W}$, por se assemelhar muito a máxima e ter uma menor intensidade.

Figura 5 - Curva de Secagem.

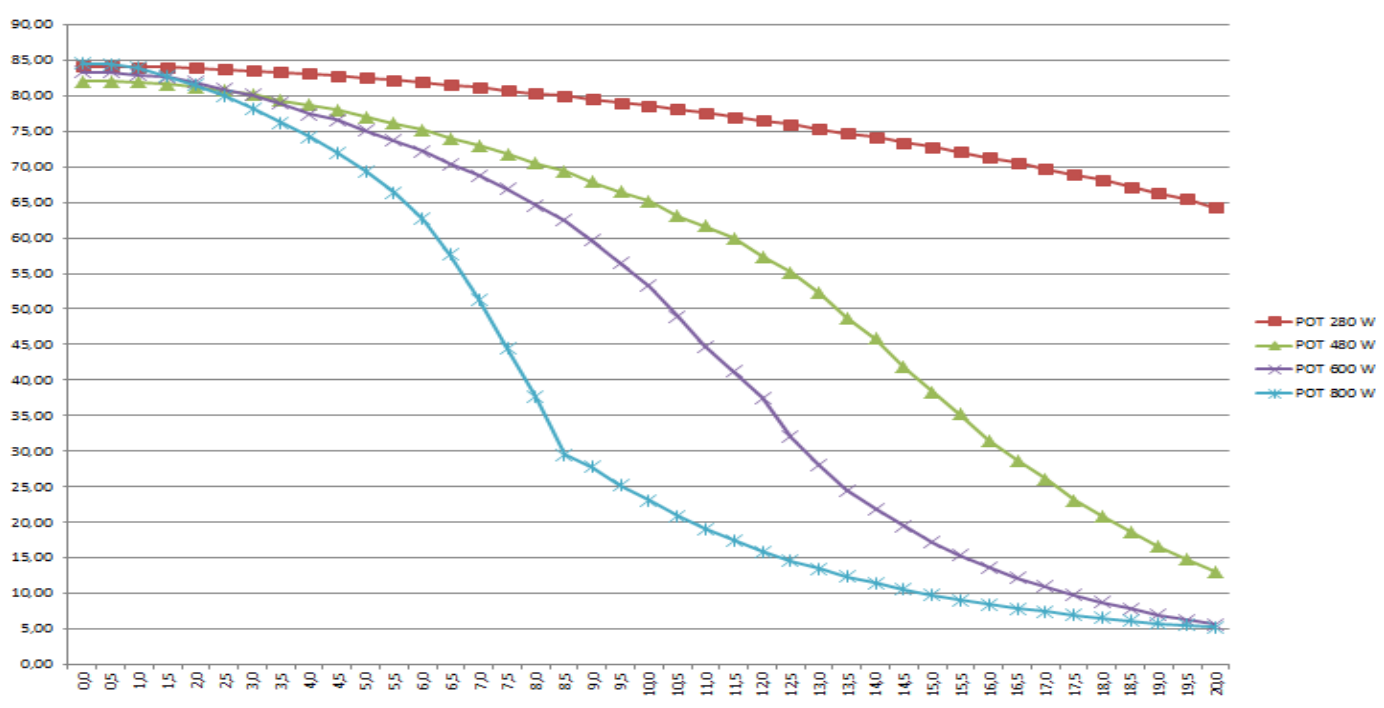




\section{CONCLUSÕES}

Podemos concluir depois de todos esses experimentos que a potencia que apresenta resultados satisfatórios é a de $480 \mathrm{~W}$, na qual todos os compostos, exceto o da acidez, apresentam um aumento em seus teores. Mostrando assim um acúmulo desses compostos após a desidratação. A queda os teores da acidez já era esperada, pois vários estudos mostram que esse composto se degrada intensamente quando expostos em altas temperaturas. Além de que em altas temperaturas a amostra pode apresentar indícios de carbonização.

Em relação às curvas de desidratação, notou-se uma queda acentuada na retirada de umidade para as potências maiores, sendo que a mesma ocorre de forma mais intensa nos minutos finais da desidratação. Diferenças entre a umidade na extremidade e centro da amostra indicam que a desidratação ocorre de forma não uniforme, das extremidades para o centro da amostra, mesmo em potências cuja retirada de umidade é quase total. Houve uma oscilação nos pontos coletados.

Assim, o método de desidratação por microondas mostrou-se uma alternativa bastante viável para desidratação de resíduos de maracujá, mantendo ou até aumentado a maioria dos compostos bioativos presentes nos mesmos.

\section{REFERÊNCIAS}

AOAC - Official Methods of Analysis Association of Official Analytical Chemists. Gaithersburg, MD: Association of Analytical Communities, 1995.

CELESTINO, C., M.; Princípios de secagens de alimentos. Planaltina, DF. Emprapa Cerrados, 2010.

PASSOS, F., R.; PENONI, N., MADEIRA, J., G.; RODRIGUES, C., C., Melhoria da composição Nutricional e Redução de custos. Universidade Federal de Visçosa- MG, 2012.

RORIZ, C.,F.,R., Aproveitamento dos Resíduos alimentícios obtidos das centrais de abastecimentos do Estado de Goiás S/A para alimentação humana. Escola de Agronomia e Engenharia de Alimentos, da Universidade Federal de Goiás, 2012.

SINGLETON, V. L \& ROSSI, J. A., Colorimetry of Total Phenolics with Phosphomolibidic Phosphotungistic Acid Reagents. American Journal of Enology and Viticulture, v. 16, p. 144-158, 1965.

SOUZA, B., B., A.; CAVALCANTI, R., M.; SILVA, F., L., G.; SILVA, M., N.. , Reaproveitamento de Resíduos Industriais - Uma viabilidade econômica e ambiental: Estudo de caso em uma empresa calçadista de João Pessoa - PB. Engenharia de Produção, 2013.

UCHÔA, A. M., Adição de Pós-Alimentícios Obtidos de Frutas Tropicais na Formulação de Biscoitos. Dissertação de Mestrado, Universidade Federal do Ceará, CE, 2007.

ZHISHEN, J.; MENGCHENG, T.; JIANMING, W., The Determination of Flavonoid Contents in Mulberry and Their Scavenging Effects on Superoxide Radicals. Food Chemistry, v. 64, p. 555-559, 1999. 